\title{
The osteogenic differentiation of rat bone marrow stromal cells cultured with dexamethasone-loaded carboxymethylchitosan/poly(amidoamine) dendrimer nanoparticles
}

\author{
Joaquim M. Oliveira ${ }^{\text {a,b,c }}$, Rui A. Sousa ${ }^{a, b}$, Noriko Kotobuki ${ }^{c}$, Mika Tadokoro $^{c}$, Motohiro Hirose ${ }^{c}$, \\ João F. Mano ${ }^{\text {a,b }}$, Rui L. Reis ${ }^{\mathrm{a}, \mathrm{b}, *}$, Hajime Ohgushi ${ }^{\mathrm{c}}$

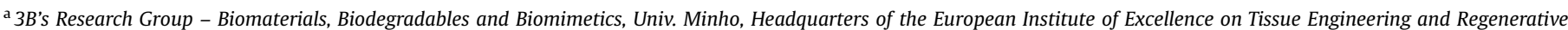 \\ Medicine, AvePark, S. Cláudio de Barco, 4806-909 Taipas, Guimarães, Portugal \\ ${ }^{\mathrm{b}}$ IBB - Institute for Biotechnology and Bioengineering, PT Government Associated Laboratory, Guimarães, Portugal \\ ${ }^{\mathrm{c}}$ Research Institute for Cell Engineering (RICE), National Institute of Advanced Industrial Science and Technology (AIST), Nakoji 3-11-46, Amagasaki, 661-0974 Hyogo, Japan
}

\section{A R T I C L E I N F O}

\section{Article history:}

Received 1 September 2008

Accepted 21 October 2008

Available online 25 November 2008

\section{Keywords:}

Bone marrow stromal cells

Dexamethasone-loaded

carboxymethylchitosan/poly(amidoamine)

dendrimer nanoparticles

Hydroxyapatite

In vitro study

Starch-polycaprolactone

Osteogenic differentiation

\begin{abstract}
A B S T R A C T
There is an increasing interest in developing novel macromolecular vehicles for the intracellular and controlled delivery of bioactive molecules, since they can allow modulation of the cellular functions in a more effective manner ex vivo, and maintain the cellular phenotype in vivo upon re-implantation. The present study was designed to investigate the effect of combining novel dexamethasone-loaded carboxymethylchitosan/poly(amidoamine) dendrimer (Dex-loaded CMCht/PAMAM) nanoparticles and, both HA and SPCL scaffolds (3D system) on the proliferation and osteogenic differentiation of rat bone marrow stromal cells (RBMSCs) in vitro. A luminescent cell viability assay using RBMSCs was performed for screening cytotoxicity of the developed HA and SPCL scaffolds. Results corroborated previous ones which have demonstrated in vitro, the superior performance of the HA and SPCL scaffolds on supporting cells adhesion and proliferation. Furthermore, this work showed that RBMSCs seeded onto the surface of both HA and SPCL scaffolds differentiate into osteoblasts when cultured in the presence of $0.01 \mathrm{mg} \mathrm{ml}^{-1}$ Dexloaded CMCht/PAMAM dendrimer nanoparticles. In addition, results demonstrated that Dex-loaded CMCht/PAMAM dendrimer nanoparticles combined with the HA enhance osteogenesis by increasing ALP activity and mineralization of the extra-cellular matrix. The pre-incubation of stem cells with these kinds of nanoparticles allows the delivery of Dex inside the cells and directly influences their cellular fate, being a promising new tool to be used in cells and tissue engineering strategies.
\end{abstract}

(c) 2008 Elsevier Ltd. All rights reserved.

\section{Introduction}

Mesenchymal stem cells (MSCs) are a valuable therapeutic tool in tissue engineering (TE) [1], since they can proliferate and differentiate either in vitro or in vivo into a multitude of distinct cellular phenotypes [2-4]. It is well known that the process of stem cell maintenance and differentiation occurs in vitro, under optimal culture conditions [5,6]. For example, it has been shown that dexamethasone (Dex) delivered as a medium supplement promotes the osteogenic differentiation of marrow stromal cells [4,7]. Despite its use in clinical practice [8], Dex and other glucocorticoids have been restricted to few applications mainly due to

\footnotetext{
* Corresponding author. 3B's Research Group - Biomaterials, Biodegradables and Biomimetics, Univ. Minho, Headquarters of the European Institute of Excellence on Tissue Engineering and Regenerative Medicine, AvePark, S. Cláudio de Barco, 4806909 Taipas, Guimarães, Portugal. Tel.: +351 253510 911; fax: +351 253510909.

E-mail address: rgreis@dep.uminho.pt (R.L. Reis).
}

adverse side-effects $[9,10]$. Therefore, the development of novel strategies that can stimulate stem cells to become osteoblasts in vitro and in vivo, and that provide a more effective treatment route with diminished complications is still regarded as a hot issue [11] that needs to be exploited further. In this context, the use of nanocarriers that possess high cellular uptake efficiency to deliver and target drugs can be seen as a possible and reliable solution [12]. Ultimately, these vehicles are expected to increase the solubility of drugs [13] and their bioavailability [14], and their delivery to the targets where they are required $[15,16]$, thus suppressing harmful secondary effects on the patients during drug/cell-based treatments.

A huge portfolio of controlled-release vehicles is being investigated for their ability to process into nanocarriers [17,18], while several new emerging nanomaterials are being studied for their biodegradability $[19,20]$ and for their controlled-release and stimuli-responsive properties [21,22]. In this context, we focus our present work on the surface engineering of poly(amidoamine) 
(PAMAM) dendrimers with natural-based and biodegradable polymers such as the water-soluble carboxymethylchitosan (CMCht) [23]. Previously [24], we have clearly demonstrated that the CMCht/PAMAM dendrimer nanoparticles are efficiently internalized by different cell types. Since glucocorticoids bind to and activate a cytoplasmatic glucocorticoid receptor [25,26], our particular interest is in the loading of these novel macromolecular architectures with Dex in order to study their internalization and effects on the proliferation and osteogenic differentiation of stem cells, in vitro and in vivo.

In this work, we applied a TE strategy consisting of the combination of stem cells and either ceramic or polymeric scaffolds as a way to qualitatively and quantitatively evaluate their performance in supporting the osteogenic differentiation of rat bone marrow stromal cells (RBMSCs) exposed to the intracellular Dex-loaded CMCht/PAMAM dendrimer nanocarrier. The herein chosen scaffolds were the macroporous HA [27] and SPCL $[28,29]$ scaffolds which have been found to exhibit a unique architecture and adequate physicochemical and biological properties to be used in bone related applications. However, the novelty of the present paper lies in deeper in vitro studies that illustrated the potential applications of combining nanoparticles and scaffolds for cells and tissue engineering. Therefore, we went a step further and reported on the osteogenic efficacy of this system, and how to make use of this potential in bone TE and regenerative medicine. In vitro studies were carried out in order to evaluate the viability of RBMSCs seeded onto the surface of the HA and SPCL scaffolds. In addition, RBMSCs-scaffold constructs' specimens were also examined using microscopic analyses to assess the cell adhesion and proliferation. Complementarily, scanning electron microscopy, LIVE/DEAD viability assay and DNA quantification were carried out after $14 \mathrm{~d}$ of culturing. Alizarin red and ALP stainings were also performed to qualitatively assess calcium deposition and ALP activity, which are parameters denoting osteogenic differentiation. Quantification of the alkaline phosphatase activity and osteocalcin content was carried out in order to evaluate the osteoblastic phenotype expression levels.

\section{Materials and methods}

2.1. Preparation of the hydroxyapatite (HA) and starch-polycaprolactone (SPCL) scaffolds

HA scaffolds were prepared by impregnating a polyurethane sacrifice sponge (PU, $5 \mathrm{~mm}$ diameter and $4 \mathrm{~mm}$ height, Eurospuma S.A., Portugal) with HA powders obtained as previously reported [27]. The elimination of the organic matrix consisted of burning the impregnated sponges in a furnace (Fornocerâmica-ATR 901, Portugal) at $900{ }^{\circ} \mathrm{C}$ for $24 \mathrm{~h}$, then sintering at $1300{ }^{\circ} \mathrm{C}$ for $3 \mathrm{~h}$.

Starch-polycaprolactone (SPCL) scaffolds were produced by adopting a two step procedure as previously reported elsewhere [28]. The material used was a blend of starch with approximately $70 \%$ by weight of poly- $\varepsilon$-caprolactone, SPCL. Briefly, fibres of SPCL were produced by melt spinning using a modular co-rotating twin screw extruder in two consecutive steps to a final draw ratio of approximately $1: 100$. Then, melt spun fibres were chopped. Fibre bundles were randomly displaced into the custom-designed mould cavities and subjected to thermal treatment at $60{ }^{\circ} \mathrm{C}$ for $30 \mathrm{~min}$ before compression and fibre bonding. SPCL scaffolds ( $5 \mathrm{~mm}$ diameter and $4 \mathrm{~mm}$ height) were obtained through cutting of fibre bonded meshes with a circular die. Standardized fabrication conditions enabled the production of scaffolds with $67.4 \pm 1.3 \%$ porosity (as determined by micro-computed tomography). More details on SPCL scaffolds can be found elsewhere [30,31].

Prior to the cell culture studies HA and SPCL scaffolds were sterilized in an ethylene oxide gas atmosphere.

\subsection{Synthesis of dexamethasone-loaded carboxymethylchitosan/poly(amidoamine)} (Dex-loaded CMCht/PAMAM) dendrimer nanoparticles

Carboxymethylchitosan (CMCht) was synthesized by a chemical modification of chitin (Sigma, Germany) as described by Chen et al. [32]. Starburst ${ }^{\circledR}$ poly(amidoamine)-carboxylic terminated dendrimers, PAMAM-CT (generation 1.5, 20\% $(\mathrm{w} / \mathrm{v})$ methanolic solution) with an ethylenediamine core were purchased from Aldrich. CMCht/PAMAM dendrimer nanoparticles were prepared stepwise as previously reported [24]. Succinctly, Dex-loaded CMCht/PAMAM dendrimer nanoparticles were prepared by means of mixing CMCht/PAMAM dendrimer nanoparticles in an aqueous solution with a dexamethasone (Dex) solution with a final concentration of $5 \times 10^{-4} \mathrm{M}$, under vigorous agitation. The mixture was then added to the precipitation media consisting of a saturated sodium carbonate (Aldrich, Germany) and acetone solution. Precipitates were collected and extensive dialysis (cellulose tubing, benzoylated for separating compounds with a cut-off of 1200 from Sigma, Germany) was carried out for $2 \mathrm{~d}$. Dex-loaded CMCht/PAMAM dendrimer nanoparticles were obtained by freezing the solution at $-80{ }^{\circ} \mathrm{C}$ and freeze-drying (Telstar-Cryodos-80, Spain).

\subsection{Characterization of the HA and SPCL scaffolds, and Dex-loaded CMCht/PAMAM} dendrimer nanoparticles

\subsubsection{Surface topography characterization}

The surface morphology and pore size of the HA scaffolds and SPCL scaffolds were examined under a scanning electron microscope, SEM (SM-300, Topcon Corporation, Tokyo, Japan). Prior to microstructure analysis, specimens were sputter coated with platinum using an Ion coater (IB-3, Eiko Engineering Ltd., Ibaraki, Japan) with a current set at $6 \mathrm{~mA}$, for a coating time of $2-3 \mathrm{~min}$.

\subsubsection{Micro-computed tomography}

The qualitative and quantitative information about the microstructure of the HA and SPCL scaffolds was obtained by micro-computed tomography, $\mu$-CT 20 equipment (SCANCO Medicals, Switzerland). The X-ray scans were acquired in high resolution mode of $11 \mu \mathrm{m} x / y / z$ [27]. Mimics ${ }^{\circledR}$ (Materialise, Belgium) was used as image processing software for $\mathrm{CT}$ reconstruction to create and visualize the $3 \mathrm{D}$ representations.

\subsubsection{Transmission electron microscopy}

The morphology of the Dex-loaded CMCht/PAMAM dendrimer nanoparticles was investigated by transmission electron microscopy, TEM (Philips CM-12, FEI Company, The Netherlands, equipped with a MEGA VIEW-II DOCU camera and Image Software Analyzer SIS NT DOCU). The nanoparticles were stained with $2 \%$ of phosphotungstic acid and placed on copper grids for observation.

\subsection{In vitro cell culture studies}

2.4.1. Isolation and culturing of rat bone marrow stromal cells (RBMSCS)

Seven-week-old Fischer 344/N male rats were purchased from Japan SLC Inc. (Shizuoka, Japan) and sacrificed in accordance with the Ethics Committee at the Tissue Engineering Research Center (Amagasaki, Japan). The epiphyseal regions of the femora were removed and marrow plugs in the femoral shafts were flushed out using Eagle's minimum essential medium (MEM, Nacalai Tesque, Japan) supplemented with $15 \%$ fetal bovine serum, FBS (JRH Biosciences, USA) and $1 \%$ antibioticantimycotic (Nacalai Tesque, Japan) solution. The RBMSCs isolation was performed under aseptic conditions. RBMSCs were transferred to a T75 $\mathrm{cm}^{2}$ culture flask and expanded in the presence of complete MEM medium at $37{ }^{\circ} \mathrm{C}$ in a $5 \% \mathrm{CO}_{2}$ incubator. Then, the culture medium was changed every 2 or $3 \mathrm{~d}$. After reaching confluency, the cells (passage 1, P1) were released from substratum with $1 \mathrm{ml}$ of $0.05 \%$ trypsin$0.53 \mathrm{~mm}$ EDTA (Invitrogen, USA) and centrifuged at $900 \mathrm{rpm}$ for $5 \mathrm{~min}$. A cell suspension was prepared and cell concentration determined using an automatic cell counter (Cell Counter Sysmex F-520, Japan).

Viability of the RBMSCs was also analyzed with a NucleoCounter (ChemoMetec A/S, Denmark) as described elsewhere [33].

\subsubsection{Cytotoxicity screening of the HA and SPCL scaffolds}

A luminescent cell viability assay [24] based on the adenosine triphosphate (ATP) quantification was performed in order to evaluate the viability of RBMSCs seeded onto the surface of the HA and SPCL scaffolds. Prior to RBMSCs seeding, the HA and SPCL scaffolds were pretreated (de-airation) to prevent air bubble formation in the pores. Scaffolds were placed in $10 \mathrm{ml}$ polystyrene tubes with ventilation caps. MEM medium was added and scaffolds were de-aired under vacuum using a $20 \mathrm{ml}$ syringe with an attached $21 \mathrm{G}$ needle. Then, each scaffold was transferred into the respective well of a non-adherent 96-well tissue culture polystyrene (TCPS) plate. RBMSCs (P1) were seeded onto the surface of the HA and SPCL scaffolds at a cell density of $5 \times 10^{2}$ cells/scaffold, $1 \times 10^{3}$ cells/scaffold, $5 \times 10^{3}$ cells/scaffold and $1 \times 10^{4}$ cells/scaffold, and cultured in MEM medium under static conditions for $24 \mathrm{~h}, 3$ and $7 \mathrm{~d}$. After each time period, the ATP content which signals the presence of metabolically active cells was measured by means of performing a CellTiter-Glo ${ }^{\circledR}$ luminescent cell viability assay (Promega Corporation, USA). Luminescence was measured in a microplate reader (Wallac ARVOsx 1420, Perkin-Elmer Life and Analytical Sciences, USA), following the protocol provided by the supplier. All experiments were carried out 3 times using 3 replicates per experimental condition.

2.4.3. Assessment of proliferation and osteogenic differentiation of RBMSCs seeded onto the surface of the HA and SPCL scaffolds and cultured with Dex-loaded CMCht/ PAMAM dendrimer nanoparticles

RBMSCs were isolated and expanded as mentioned above. HA and SPCL scaffolds were placed in each well of a 96-well TCPS plate. Then, $1 \times 10^{6}$ RBMSCs (P1) were added per each HA and SPCL scaffold, and the constructs were cultured in complete 

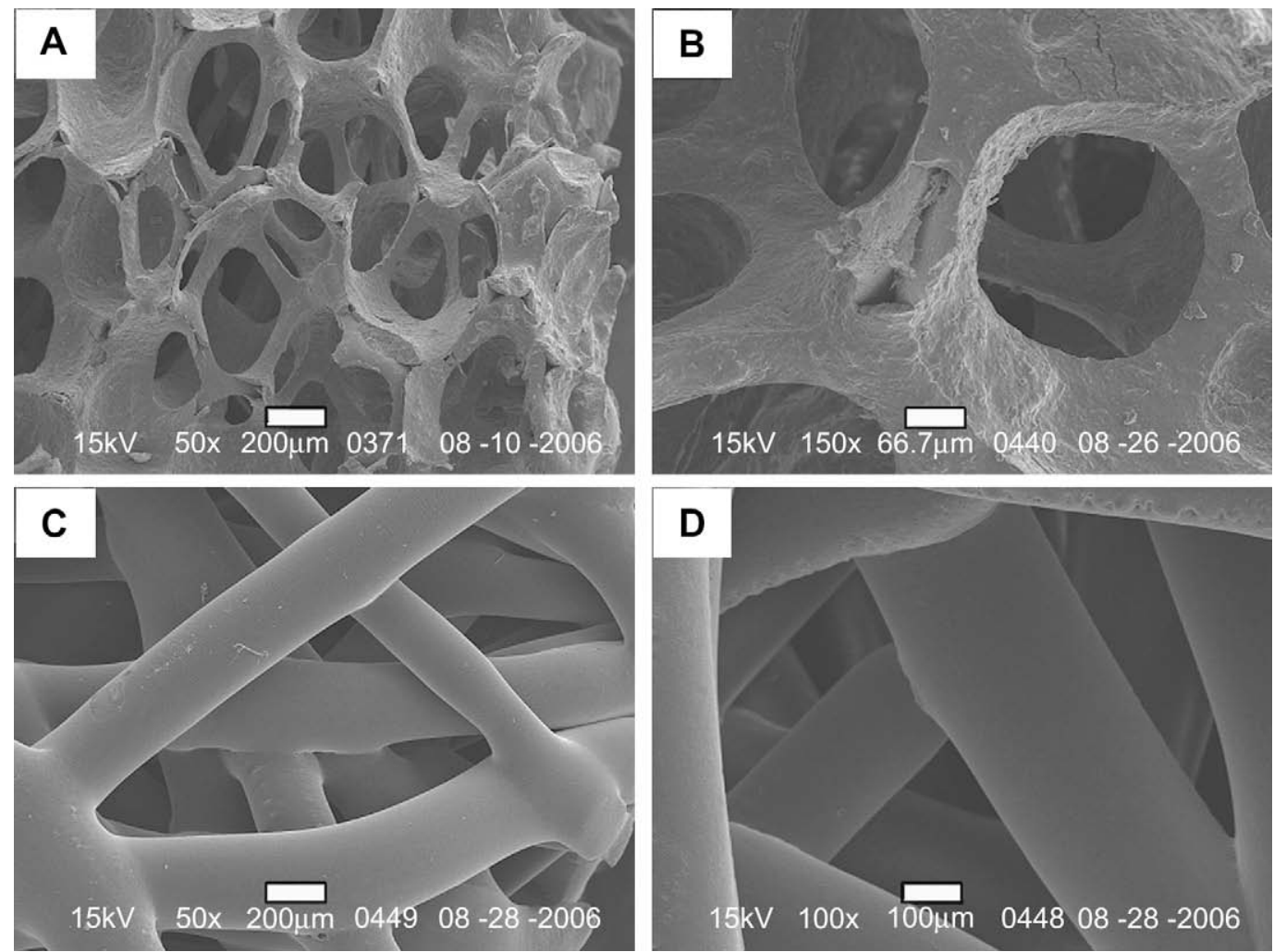

Fig. 1. SEM micrographs of the HA (A-B) and SPCL (C-D) scaffolds.

MEM medium under standard culture conditions for the period of $12 \mathrm{~h}$ to allow cell adhesion. After that time, cell-scaffold constructs were transferred to a non-treated and non-protein coated flat bottom 12-well TCPS plate (Nunc, Japan), the different culture medium was added, and RBMSCs were cultured for times up to $14 \mathrm{~d}$. RBMSCs were exposed to a MEM medium supplemented with $0.01 \mathrm{mg} \mathrm{ml}^{-1}$ Dex-loaded CMCht/PAMAM dendrimer nanoparticles, $0.28 \mathrm{~mm}$ ascorbic acid (Wako Pure Chemicals, Japan) and $10 \mathrm{~mm} \beta$-glycerophosphate (Sigma, USA). RBMSCS were also cultured in a complete MEM medium (negative control for osteogenic differentiation). A complete MEM medium supplemented with $10^{-8} \mathrm{M}$ Dex, $0.28 \mathrm{~mm}$ ascorbic acid and $10 \mathrm{~mm} \beta$-glycerophosphate was used as the positive control for osteogenic differentiation. All experiments were carried out 3 times using a minimum of 3 replicates per experimental condition.

\subsubsection{LIVE/DEAD viability assay}

Cell adhesion and proliferation were also investigated with a LIVE/DEAD viability assay kit (Molecular Probes, USA) after $14 \mathrm{~d}$ of culturing. RBMSCs-scaffold constructs were incubated with two probes, calceín-AM (green colour) and ethidium homodimer-1 (bright red colour), for intracellular esterase activity and plasma membrane integrity, respectively [34]. Then, RBMSCs-scaffold construct specimens were washed with $\mathrm{Ca}$ and Mg-free PBS solution and observed under a 3D

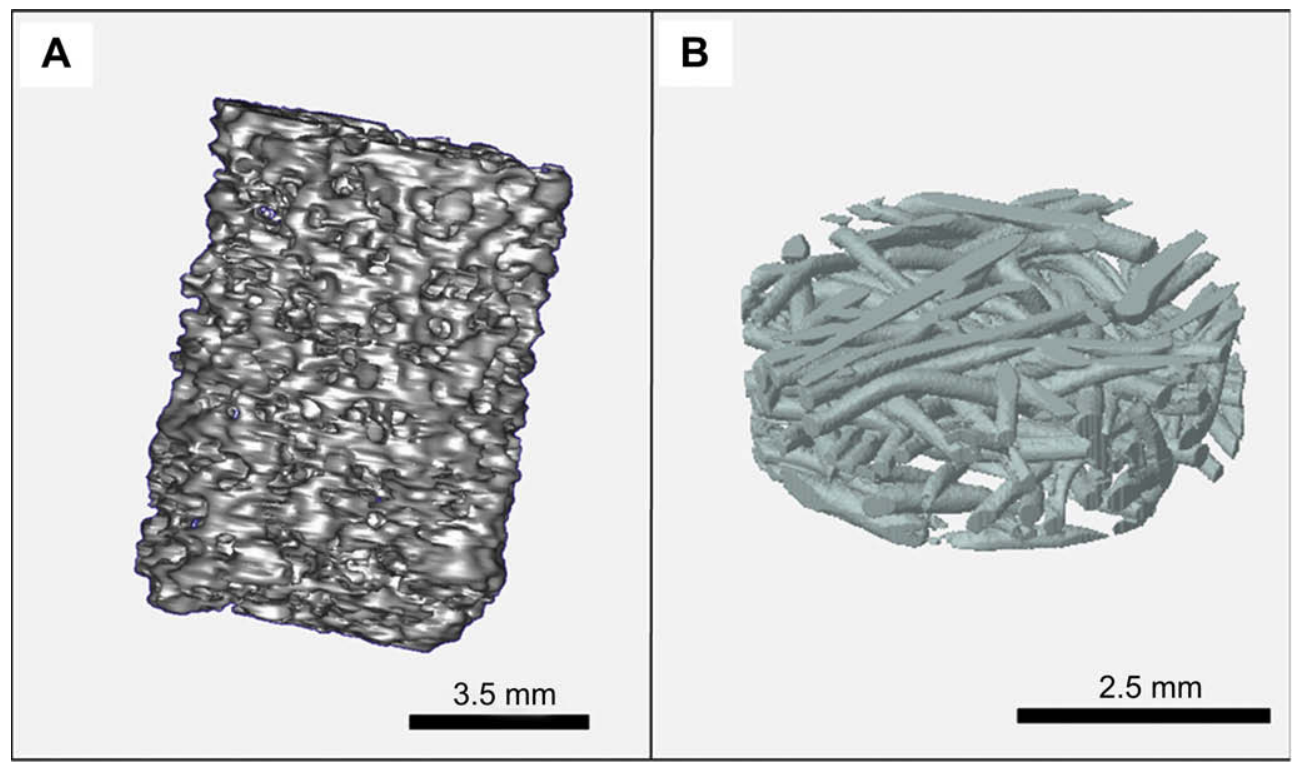

Fig. 2. 3D $\mu-C T$ images of the HA (A) and SPCL (B) scaffolds. 


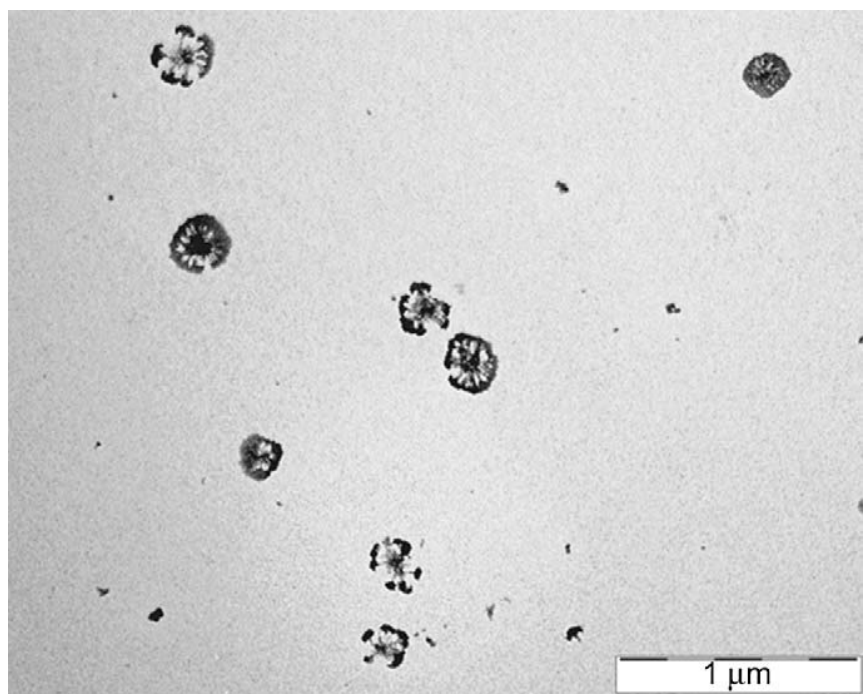

Fig. 3. TEM image showing the morphology of the Dex-loaded CMCht/PAMAM dendrimer nanoparticles.

fluorescence microscope (Olympus SZX12 stereomicroscope, OLYMPUS Co. Ltd., Japan). RBMSCs-scaffold constructs' specimens were also prepared for SEM observation using standard fixative and dehydration methods.

\subsubsection{DNA quantification}

DNA quantification was performed using the nuclear dye Hoechst 33258 (Nacalai Tesque, Japan) according to the method previously described [34]. Prior to the assay, the RBMSCs-scaffold constructs were washed with a Ca and Mg-free PBS solution. Then, constructs were transferred to a $2 \mathrm{ml}$ eppendorf, pulverized with zirconia's balls (milling time of $\sim 2$ min at 25 shakes $\mathrm{s}^{-1}$ ) using a ball mixer mill (Retsch GmbH, Germany), and sonicated in $0.2 \%$ Triton-X (Nacalai Tesque, Japan) solution for $5 \mathrm{~min}$. Finally, the samples were sonicated and the DNA quantification carried out. The standard DNA solutions were prepared using salmon sperm DNA (Invitrogen, USA).

\subsubsection{Qualitative analysis of mineralization}

Alizarin red S staining was performed to investigate possible calcium deposition after $14 \mathrm{~d}$ of culturing. RBMSCs-scaffold construct specimens were washed twice with Ca and Mg-free PBS solution and cells fixed with 95\% ethanol for 15 min [35]. The fixed cells were then washed once with PBS and stained with $5 \mathrm{mg} \mathrm{ml}^{-1}$ Alizarin red $\mathrm{S}$ in $\mathrm{Ca}$ and $\mathrm{Mg}$-free PBS solution for $5 \mathrm{~min}$ at room temperature. After a washing step with ultra-pure water, RBMSCs-scaffold construct specimens were examined under a 3D fluorescence microscope.

\subsubsection{Qualitative and quantitative analysis of alkaline phosphatase (ALP)}

ALP activity was investigated either qualitatively and quantitatively in order to evaluate osteoblastic differentiation. For the ALP staining the RBMSCs-scaffold construct specimens were washed twice with PBS, after $14 \mathrm{~d}$ of culturing. Cells were fixed with $4 \%$ paraformaldehyde/Ca and Mg-free PBS solution for $15 \mathrm{~min}$ at $4{ }^{\circ} \mathrm{C}$. The RBMSCs-scaffold construct specimens were washed twice with AMP buffer ( $56 \mathrm{~mm}$ of 2-amino-2-methyl-1,3-propanediol in ultra-pure water, $\mathrm{pH} 9.9$ ) and then soaked with staining solution $0.5 \mathrm{mg}$ naphtol AS-MX phosphate and $0.5 \mathrm{mg}$ fast red violet LB salt per ml, in AMP buffer. RBMSCs-scaffold construct specimens were incubated for $10 \mathrm{~min}$ at room temperature, washed with $\mathrm{Ca}$ and Mg-free PBS solution and examined under a 3D fluorescence microscope.

The remaining sonicated suspensions obtained from the DNA quantification assay were used to determine ALP levels. Prior to analysis the samples were sonicated once and centrifuged at $12,000 \mathrm{rpm}$ for $1 \mathrm{~min}$ at $4{ }^{\circ} \mathrm{C}$. To each well of a 96 -well plate, an aliquot of supernatant and p-nytrophenyl phosphate substrate (ZYMED ${ }^{\circledR}$ Laboratories, Invitrogen, USA), was added following the method described elsewhere [33] with minor modifications. Standards were prepared with $p$-nytrophenol, pNP. Triplicates were made for each sample and standard. Absorbance was read at 405 nm (Wallac ARVOsx 1420, Perkin-Elmer Life and Analytical Sciences, USA), and sample concentrations were read off from the standard graph. Enzyme activity was expressed as nmol of pNP released/scaffold/30 min and normalized by DNA content.

\subsubsection{Osteocalcin content determined by enzyme-linked immunosorbent assay} (ELISA)

The remnants of each sample used for the ALP/DNA assays were treated with a $20 \%$ formic acid solution and stored at $4{ }^{\circ} \mathrm{C}$ for $2-3 \mathrm{~d}$. After that time, samples were centrifuged at $15,000 \mathrm{rpm}$ for $10 \mathrm{~min}$ at $4{ }^{\circ} \mathrm{C}$. The supernatant was passed through a Sephadex ${ }^{\mathrm{TM}} \mathrm{G}-25$ column (GE healthcare, Sweden) for de-salting, and concentrated in order to carry out the ELISA assay. A Rat Osteocalcin EIA kit (No. BT-460, Biomedical Technologies Inc., MA, USA) was used following the instructions provided by the supplier. Data was read off from the standard curve obtained with human osteocalcin and expressed as ng of deposited osteocalcin per $\mu \mathrm{g}$ of DNA

\section{Results and discussion}

\subsection{Morphology of the HA and SPCL scaffolds, and Dex-loaded CMCht/PAMAM dendrimer nanoparticles}

It is well known that the ability of a scaffold to support cells proliferation and differentiation is one of the key issues for the success of a tissue engineered cells-scaffold construct. In the current work, an extensive in vitro study was carried out in order to investigate the effect of the intracellular delivery of dexamethasone by the carboxymethylchitosan/poly(amidoamine) dendrimer (Dexloaded CMCht/PAMAM) nanoparticles supplemented from a culture medium on the proliferation and osteogenic differentiation of RBMSCs when cultured onto the surface of two types of scaffolds. From Fig. 1, it is possible to observe the microstructure of the HA (A-B) and SPCL (C-D) scaffolds examined under SEM. Fig. 1A and $B$ revealed that the architecture of the obtained $H A$ scaffolds possess a trabeculae-like structure and highly interconnected macropores. Fig. 1C and D shows the typical SPCL macroporosity which can be obtained by randomly assembling the fibres. The polymeric scaffolds also exhibited a high level of interconnectivity.

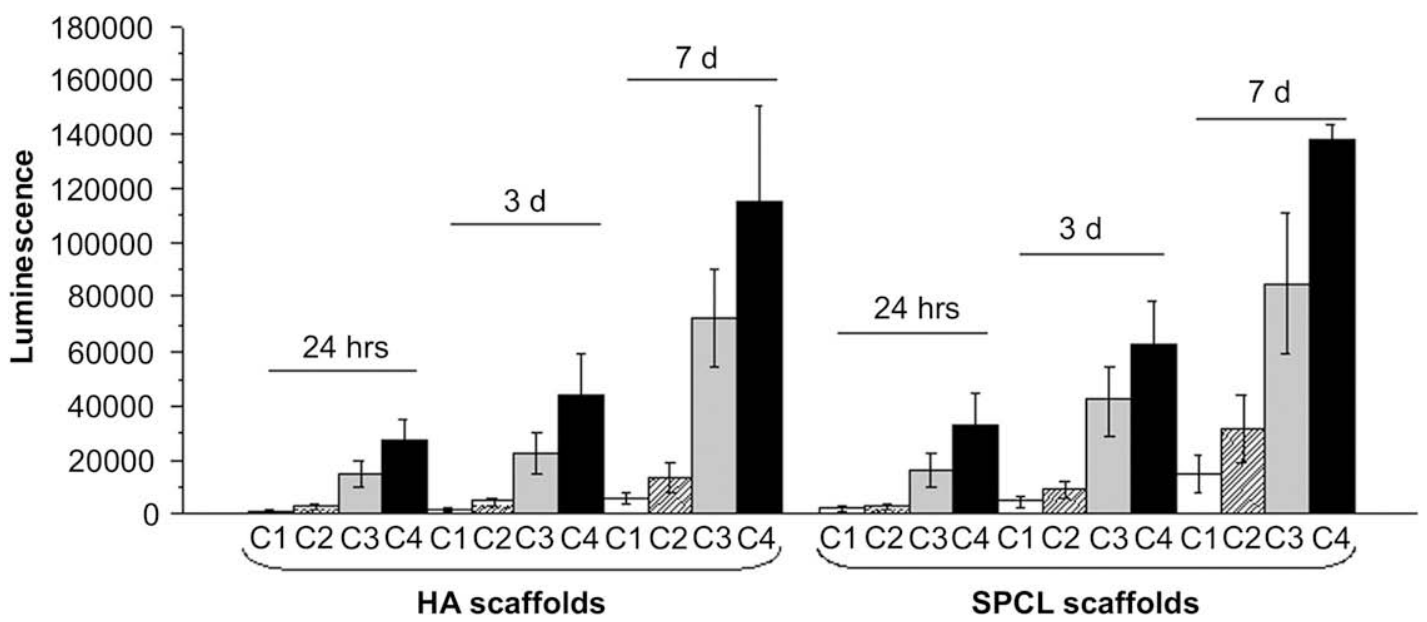

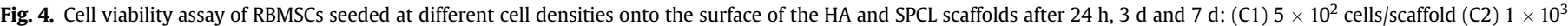

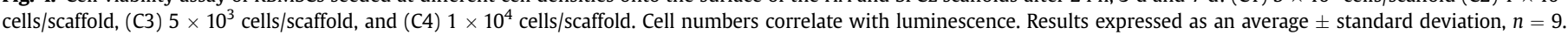



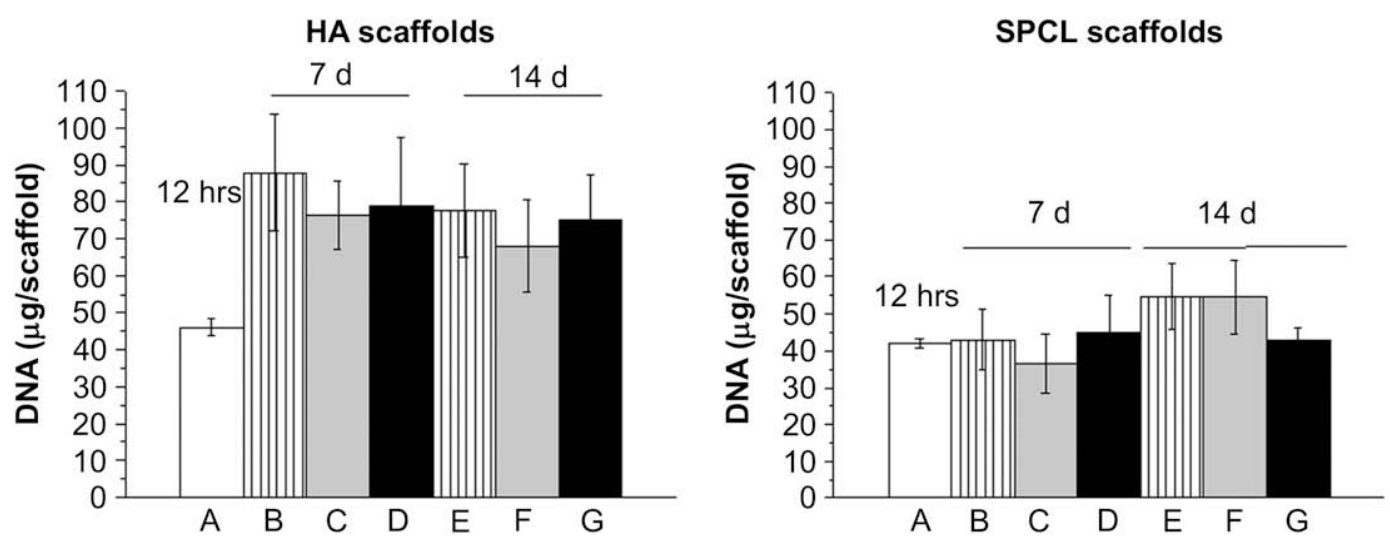

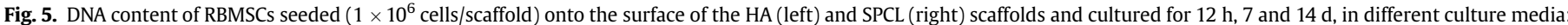

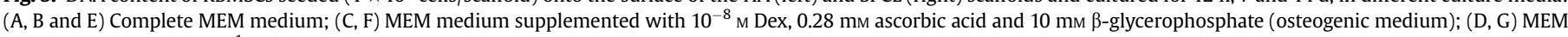

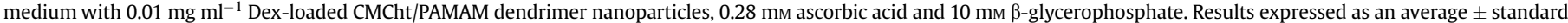
deviation, $n=9$.

Several groups $[27,29,31]$ have shown that these scaffolds exhibit adequate porosity and mechanical properties to support cell adhesion and proliferation and tissue ingrowth upon implantation of the construct. Moreover, we have also demonstrated that these starchbased scaffolds are biodegradable, and thus have the potential to be used in tissue engineering strategies to regenerate bone tissue defects.

Fig. 2 shows the 3D micro-computed tomography images of the HA and SPCL scaffolds. This study revealed that the HA scaffolds possess a mean porosity of $67.8 \pm 5.1 \%$ and pore size in the range of 50-600 $\mu \mathrm{m}$. The SPCL scaffolds showed a mean porosity of $67.4 \pm 1.3 \%$ and pore size in the range of $50-1000 \mu \mathrm{m}$. The selected scaffolds present a similar porosity and pore size as well as high levels of interconnectivity, which is ideal for carrying out a comparative study in terms of scaffold composition as these features play a critical role in bone formation in vitro and in vivo [36]. Issues that will not be addressed in the present work are of course related to the mechanical properties and degradation rate of the scaffolds, but more details on this can be found elsewhere [31].

Fig. 3 shows the TEM image of the developed Dex-loaded CMCht/ PAMAM dendrimer nanoparticles. It can be seen that the novel macromolecular nanocarriers possess a dendron-like morphology. These have been shown to be effective in the loading and controlled

\section{HA scaffolds}
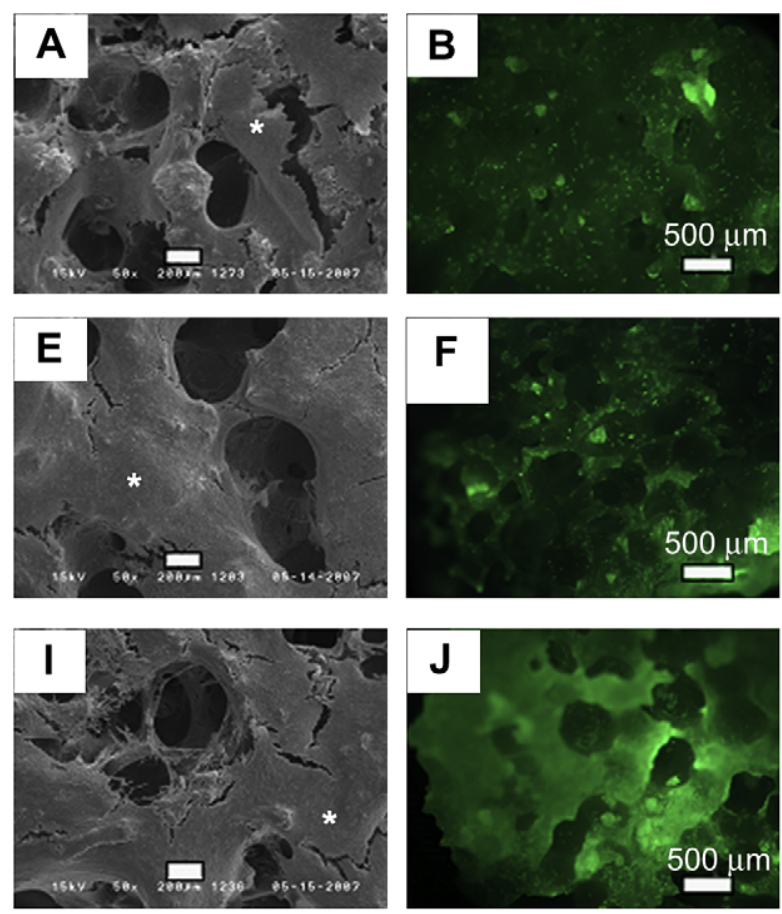

SPCL scaffolds
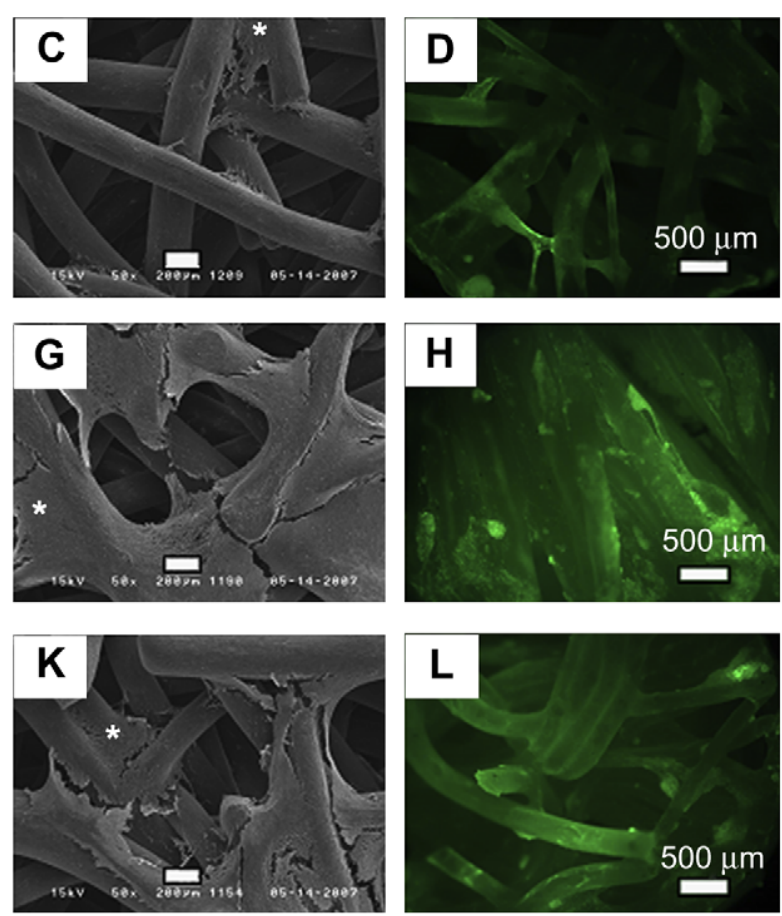

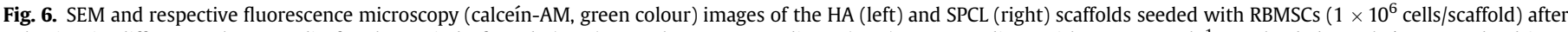

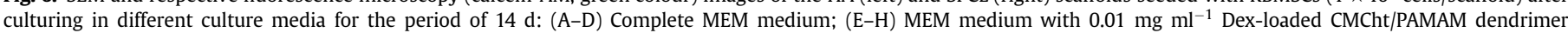

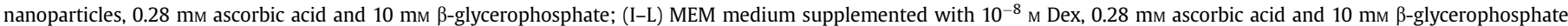
(osteogenic medium). It is also possible to observe that cells perfectly adhere, spread actively and presented a flatten morphology $(*)$. 
HA scaffolds
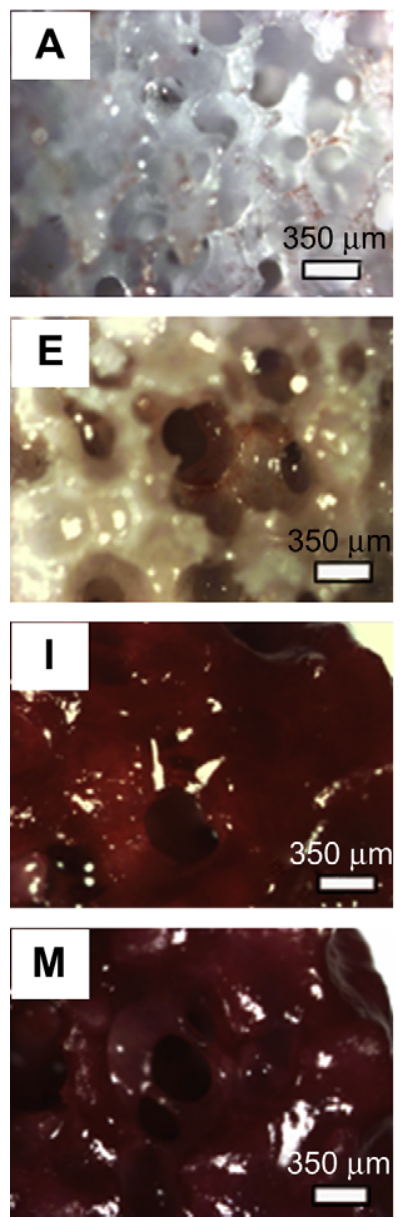
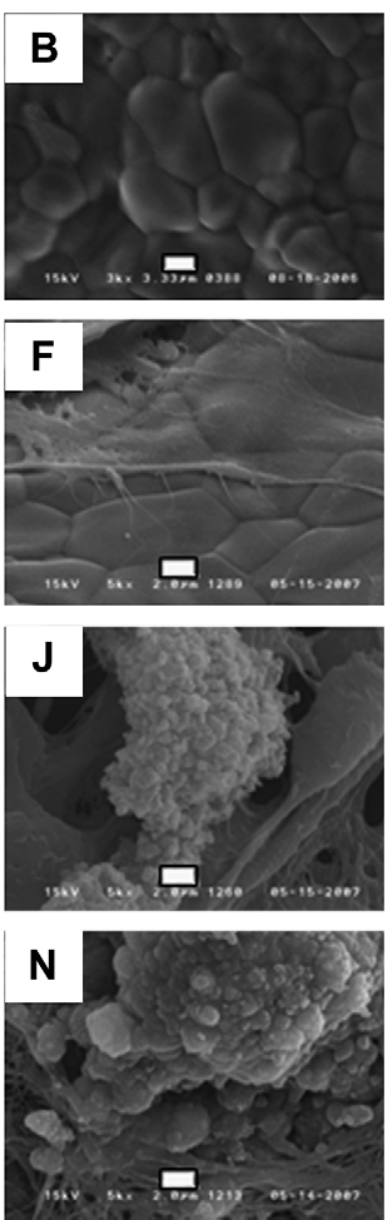

SPCL scaffolds
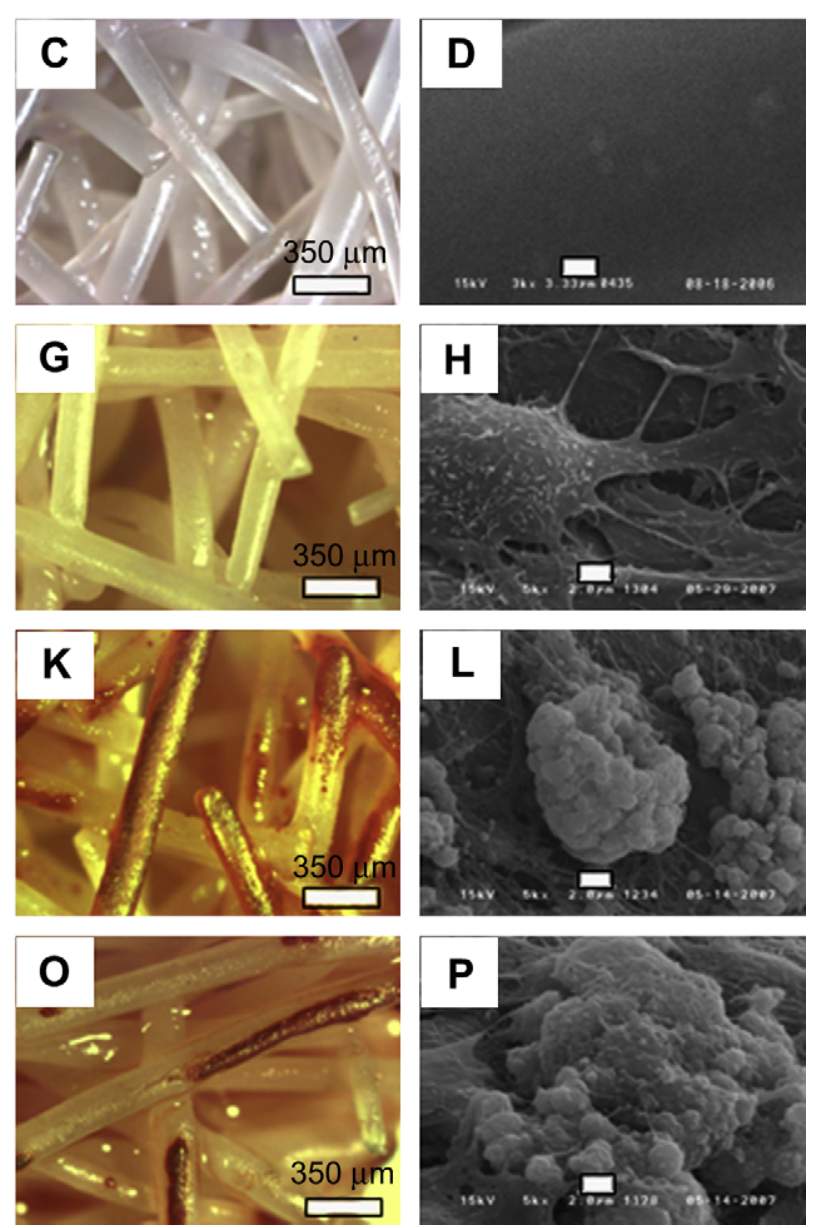

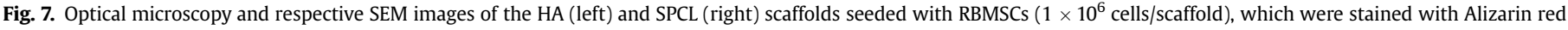

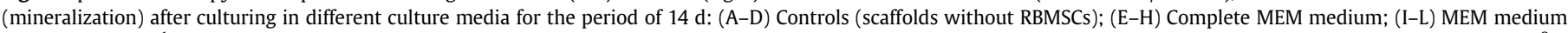

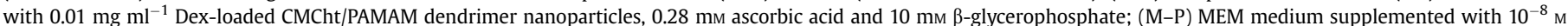
Dex, $0.28 \mathrm{~mm}$ ascorbic acid and $10 \mathrm{~mm} \beta$-glycerophosphate (osteogenic medium).

release of Dex [24]. In this study, we have also demonstrated that the Dex-loaded CMCht/PAMAM dendrimer nanoparticles did not exhibit significant cytotoxicity in the range of concentrations below $1 \mathrm{mg} \mathrm{ml}^{-1}$ and fluorescent probe labelled nanoparticles were found to be internalized with high efficiency by different cell types. In this first study, we also proved that the Dex-loaded CMCht/PAMAM dendrimer nanoparticles promote the osteogenic differentiation of rat bone marrow stromal cells in a 2D system, in vitro.

\subsection{Rat bone marrow stromal cells viability, adhesion and proliferation}

A luminescent cell viability assay based on adenosine triphosphate (ATP) quantification was performed to evaluate the viability of RBMSCs seeded at different cell densities onto the surface of the HA and SPCL scaffolds, and results are disclosed in Fig. 4. This assay is a feasible test for assessing the cytotoxicity of materials, since it signals the presence of metabolically active cells. Results have shown that the HA and SPCL materials are not cytotoxic over RBMSCs. As seen in the present work, no significant differences in the RBMSCs viability were observed when culturing on the surface of the HA as compared to the SPCL scaffolds. By its turn, it is possible to observe that the initial RBMSCs seeding density affects the viability (ATP content) of RBMSCs.
Additional studies were carried out to evaluate the capacity of HA and SPCL scaffolds to support the proliferation and differentiation of rat bone marrow stromal cells (RBMSCs) after exposure to Dex-loaded CMCht/PAMAM dendrimer nanoparticles.

In the present paper, RBMSCs proliferation was investigated by DNA quantification (Fig. 5). From that figure it is possible to observe that the cell seeding efficiency is similar for HA and SPCL scaffolds as observed by the DNA content after $12 \mathrm{~h}$ of culturing. However, a slightly higher cellular density was detected for the HA as compared to that for SPCL, after 7 and $14 \mathrm{~d}$. This result shows that the HA scaffolds allow for a higher proliferation of the RBMSCs. To a certain extent, this observation may also be related with the fact that proliferation rates are reduced during differentiation [37], as seen by lower cell numbers in cultures when osteogenic factors were present. Then, RBMSCs-scaffold constructs were also examined under microscopic analyses in order to assess cell adhesion and proliferation, after $14 \mathrm{~d}$ of culturing (Fig. 6). It is possible to observe a higher cellular density on the surface of the HA as compared to the SPCL. This data thus reflects the findings of the DNA quantification. This data also indicates that cells adhere perfectly, spread actively, and present a flattened morphology $(*)$. Moreover, the (calcein-AM, green colour) images of the RBMSCsHA and SPCL constructs revealed that cells were alive, after $14 \mathrm{~d}$ (for interpretation of colour in Fig. 6, the reader is referred to the web 

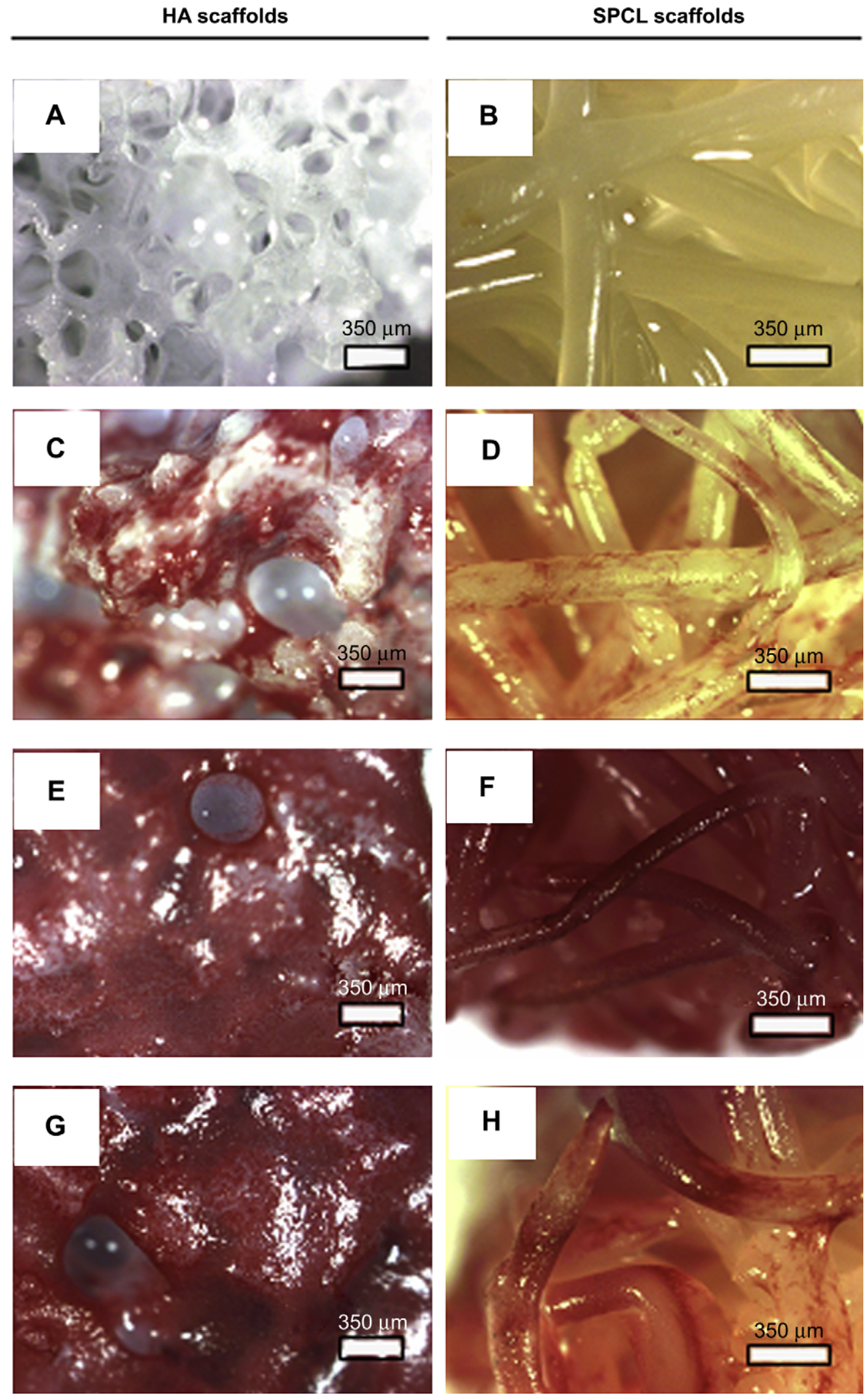

Fig. 8. Optical microscopy images of the HA (left) and SPCL (right) scaffolds seeded with RBMSCs $\left(1 \times 10^{6}\right.$ cells/scaffold) which were stained for ALP after culturing in different culture medium for the period of $14 \mathrm{~d}$ : (A, B) Controls (scaffolds without RBMSCs); (C, D) Complete MEM medium; (E, F) MEM medium with $0.01 \mathrm{mg} \mathrm{ml}^{-1}$ Dex-loaded CMCht/ PAMAM dendrimer nanoparticles, $0.28 \mathrm{~mm}$ ascorbic acid and $10 \mathrm{~mm} \beta$-glycerophosphate; (G, H) MEM medium supplemented with $10^{-8} \mathrm{M}$ Dex $0.28 \mathrm{~mm}$ ascorbic acid and $10 \mathrm{~mm} \beta$ glycerophosphate (osteogenic medium). 
version of this article). Despite the high cellular density it is clear that cells did not obstruct the pores of either. This is an important condition, since the overall performance of the construct [38-40] may be affected by limiting the diffusion of nutrients, oxygen, and metabolites to or from its core.

\subsection{Effect of the Dex-loaded CMCht/PAMAM dendrimer nanoparticles on the osteogenic differentiation of rat bone marrow stromal cells}

In the present study we have also investigated the osteogenic differentiation of RBMSCs seeded onto the surface of the HA and SPCL scaffolds that were cultured in: (i) absence of Dex and (ii) with Dex delivered as a medium supplement and via cellular uptake using the CMCht/PAMAM dendrimer nanoparticles. Mendes et al. [29] showed that the SPCL supports the proliferation and osteogenic differentiation of RBMSCs, in vitro. Despite the in vitro and in vivo characterization on the performance of the SPCL scaffolds, the report lacks in quantitative data. To our knowledge, no qualitative and quantitative studies were performed to investigate the effect of combining Dex-loaded CMCht/PAMAM dendrimer nanoparticles and both HA and SPCL scaffolds (3D system) on the osteogenic differentiation of the RBMSCs, in vitro.

Production of mineral deposits is an important indicator of osteogenesis and osteogenic differentiation [41,42]. In order to be able to assess mineralization, calcium staining (Alizarin red) and SEM analyses of RBMSCs-scaffold constructs cultured in different culture media were carried out (Fig. 7). At $14 \mathrm{~d}$, it was possible to observe a higher calcium deposition in the RBMSCs-scaffold constructs exposed to Dex-loaded CMCht/PAMAM dendrimer nanoparticles as compared to that of RBMSCs-scaffold constructs cultured in the standard culture medium (Fig. 7I, K, and E, G). The extent of mineralization in cultures exposed to Dex-loaded CMCht/ PAMAM dendrimer nanoparticles at a final concentration of $0.01 \mathrm{mg} \mathrm{ml}^{-1}$ was of the same magnitude as for cultures exposed to a standard osteogenic media (Fig. 7I, K and M, O). Moreover, from SEM images it is possible to observe the typical mineralized nodules (Fig. 7J, L and N, P), which are not seen in RBMSCs-scaffold constructs cultured in complete MEM medium (Fig. 7F and $\mathrm{H}$ ).

Finally, the osteoblastic phenotype expression levels were evaluated both, qualitatively and quantitatively for alkaline phosphatase and osteocalcin, which are known to be the early and late markers of osteogenic differentiation [43], respectively. It is well known that Dex triggers the osteogenic differentiation of MSCs at an early stage and directs the cells toward terminal maturation at the late stages of differentiation and matrix mineralization [44].
Thus, we hypothesized that the continuous exposure of RBMSCs to Dex via the sustained release from the nanoparticles, either intracellularly or in culture media results in the differentiation of RBMSCs into mature osteoblasts. Fig. 8 shows the ALP staining of RBMSCs-scaffold constructs after culturing in a different culture medium for a period of $14 \mathrm{~d}$. As seen for mineralization, the ALP activity is higher for cultures in which RBMSCs were exposed to Dex-loaded CMCht/PAMAM dendrimer nanoparticles and osteogenic medium (Fig. 8E, F and G, H). These findings demonstrate strong evidence that osteogenic differentiation only occurred in cultures with Dex either supplemented from culture media and delivered via the Dex-loaded CMCht/PAMAM dendrimer nanoparticles.

The ALP activity per DNA content of the HA (left) and SPCL (right) scaffolds seeded with RBMSCs and cultured in different culture media for a period of $12 \mathrm{~h}, 7$ and $14 \mathrm{~d}$ is presented in Fig. 9. It is possible to observe that ALP activity is increased in cultures where RBMSCs-scaffold constructs were exposed to Dex, i.e. Dexloaded CMCht/PAMAM dendrimer nanoparticles and osteogenic medium. The present data is not surprising, since the in vitro release studies of Dex from the CMCht/PAMAM dendrimer nanoparticles [24] revealed that Dex concentration resembles to that of osteogenic media. In addition, a significant increase in the ALP activity of RBMSCs-HA scaffold constructs that were cultured with Dex delivered via the CMCht/PAMAM dendrimer nanoparticles was observed as compared to the constructs supplemented with Dex in culture media, after $7 \mathrm{~d}$. In contrast, the ALP activity is higher when RBMSCs are cultured with $10^{-8} \mathrm{M}$ Dex supplied from culture medium (Fig. 9 right, F), after $14 \mathrm{~d}$. No significant differences in the ALP activity were observed for RBMSCs-SPCL scaffold constructs, after $7 \mathrm{~d}$ although, sub-figure (right, $\mathrm{G}$ ) shows a higher ALP activity in the RBMSCs-SPCL constructs that were cultured with Dex-loaded CMCht/PAMAM dendrimer nanoparticles after $14 \mathrm{~d}$. We have also observed that ALP activity is higher for the RBMSCs-HA constructs as compared to that for the RBMSCs-SPCL constructs. Thus, results demonstrated that Dex-loaded CMCht/PAMAM dendrimer nanoparticles combined with HA enhance osteogenesis by increasing ALP activity and mineralization of the extra-cellular matrix. Therefore, the present data shows that the Dex-loaded CMCht/ PAMAM dendrimer nanoparticle may be useful in TE strategies since it promotes the early osteogenic differentiation of RBMSCs. In its turn, this data corroborates previous works $[27,42,45]$ that demonstrated the important role of HA in the adhesion, proliferation and osteogenic differentiation of the RBMSCs, in vitro and in vivo. This data is not surprising since HA which has a crystal structure similar to that of bone mineral [46], and are considered
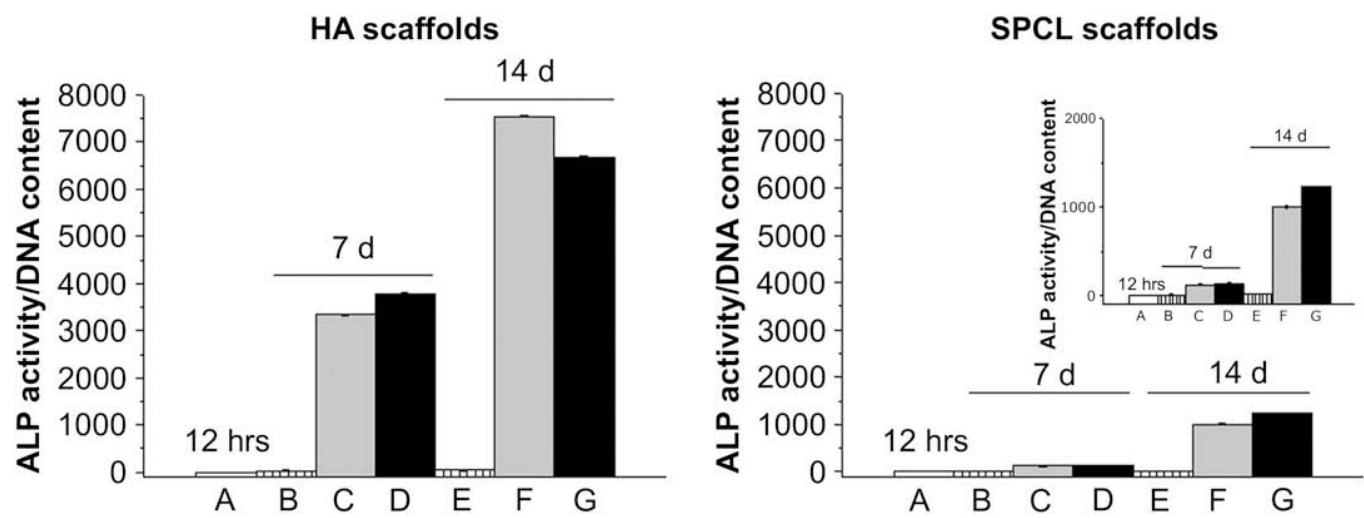

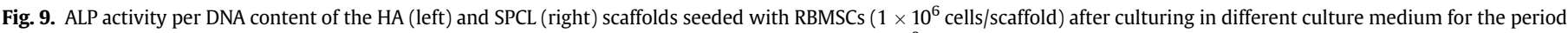

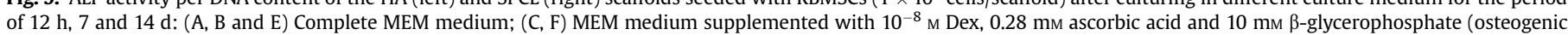

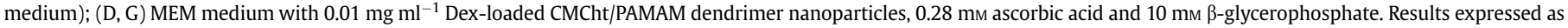
an average \pm standard deviation, $n=9$. 
HA scaffolds

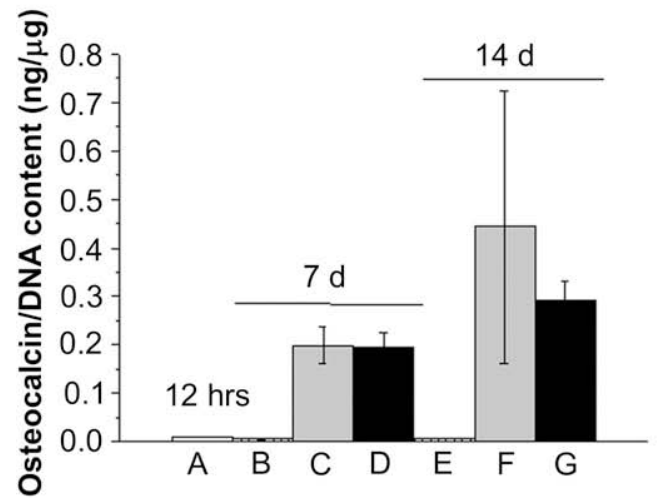

SPCL scaffolds

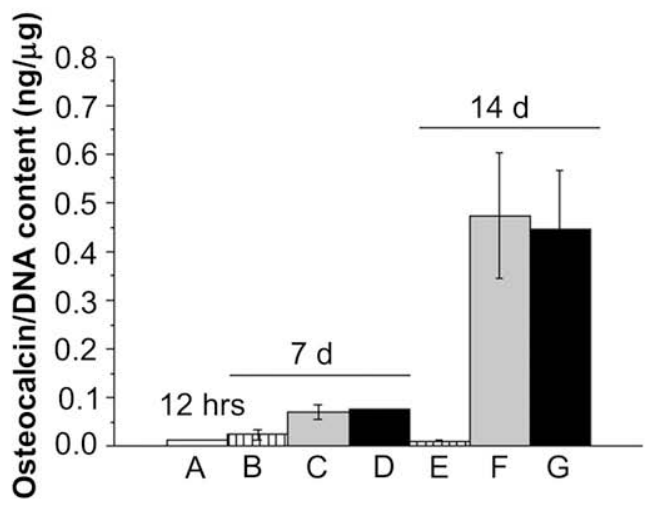

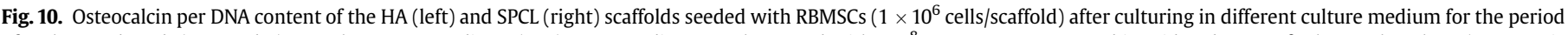

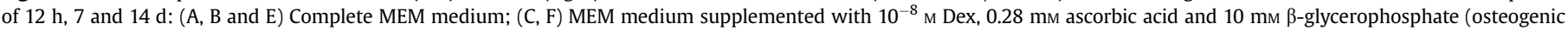

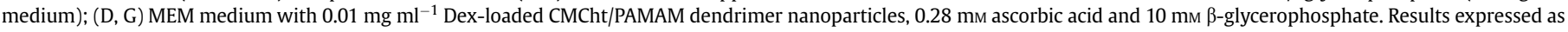
an average \pm standard deviation, $n=9$.

the 'gold-standard' of the osteoconductive materials. The obtained results also demonstrated that SPCL scaffolds are effective in supporting the osteogenic differentiation of RBMSCs, since ALP activity is in the same order of magnitude to that of RBMSCs-HA constructs. On the other hand, the SPCL scaffolds have been shown [31] to be degraded enzymatically, which allows an increase in the scaffold porosity over time and consequently may favour tissue ingrowth during implantation time.

Fig. 10 shows the content of the late osteogenic marker and bone-specific osteocalcin normalized by DNA content of RBMSCs cultured onto the surface of the HA (left) and SPCL (right) scaffolds and exposed to a different culture medium for the period of $12 \mathrm{~h}, 7$ and $14 \mathrm{~d}$. This data corroborates the previous ALP assay demonstrating that RBMSCs differentiate into osteoblasts when culturing in the presence of Dex-loaded CMCht/PAMAM dendrimer nanoparticles and osteogenic medium. However, no significant differences in osteocalcin content were observed for the RBMSCs-HA and RBMSCs-SPCL scaffold constructs supplemented with Dex delivered via the CMCht/PAMAM dendrimer nanoparticles and free in culture media, after 7 and $14 \mathrm{~d}$ of culturing. In the light of these results, we have shown that RBMSCs proliferated well, and both differentiate into osteoblasts and organize into a mineralized matrix by combining Dex-loaded CMCht/PAMAM dendrimer nanoparticles and scaffolds (3D systems), in vitro.

This work has demonstrated the efficacy of the system Dexloaded CMCht/PAMAM dendrimer nanoparticles and scaffolds in promoting the proliferation and osteodifferentiation of RBMSCs, and the success in the intracellular delivery of Dex, in vitro. Thus, it is conceivable that intracellular controlled drug delivery using biodegradable nanocarriers or cell-based carrying nanoparticles' strategies may be an excellent candidate for in vivo TE applications, as these nanosystems may possibly to: (i) reduce the drug dosage needs and (ii) improve efficacy, since the drug would only concentrate in the damaged/diseased cells and tissues.

\section{Conclusion}

In this work we demonstrate the biological performance of previously prepared macroporous HA and SPCL scaffolds. These have shown to be adequate for culturing RBMSCs, namely for adhesion, proliferation and osteogenic differentiation. Results showed that the RBMSCs proliferation and osteogenic differentiation are favored when cultured onto the surface of the HA scaffolds, but the results obtained for SPCL are quite similar and much better than one could expect for a biodegradable polymer. On the other hand, the biochemical data presented herein demonstrated that the Dex-loaded CMCht/PAMAM dendrimer nanoparticles enhanced the early osteogenic differentiation of RBMSCs in vitro. Therefore, the Dex-loaded CMCht/PAMAM dendrimer nanoparticles may be used as intracellular nanocarriers of biological agents being able to modulate the behaviour of stem cells.

\section{Acknowledgements}

The authors thank the funds provided by Portuguese Foundation for Science and Technology (FCT) through POCTI and FEDER programmes including project ProteoLight (PTDC/FIS/68517/2006). This work was also carried out with the support of the European Union funded STREP Project HIPPOCRATES (NMP3-CT-2003505758) and European NoE EXPERTISSUES (NMP3-CT-2004500283). The funding provided by Canon Foundation in Europe is gratefully acknowledged.

\section{Appendix}

Figures with essential colour discrimination. Certain figures in this article, in particular Figures 6,7 and 8 , are difficult to interpret in black and white. The full colour images can be found in the on-line version, at doi: 10.1016/j.biomaterials.2008.10.024.

\section{References}

[1] Langer R, Vacanti J. Tissue engineering. Science 1993;260:920-6.

[2] Rice CM, Scolding NJ. Autologous bone marrow stem cells - properties and advantages. J Neurol Sci 2008;265(1-2):59.

[3] Ke Z, Zhou F, Wang L, Chen S, Liu F, Fan X, et al. Down-regulation of Wnt signaling could promote bone marrow-derived mesenchymal stem cells to differentiate into hepatocytes. Biochem Biophys Res Commun 2008;367(2):342.

[4] Ciapetti G, Ambrosio L, Marletta G, Baldini N, Giunti A. Human bone marrow stromal cells: in vitro expansion and differentiation for bone engineering. Biomaterials 2006;27(36):6150.

[5] Lei Z, Yongda L, Jun M, Yingyu S, Shaoju Z, Xinwen Z, et al. Culture and neural differentiation of rat bone marrow mesenchymal stem cells in vitro. Cell Biol Int 2007;31(9):916.

[6] Donzelli E, Salvade A, Mimo P, Vigano M, Morrone M, Papagna R, et al. Mesenchymal stem cells cultured on a collagen scaffold: in vitro osteogenic differentiation. Arch Oral Biol 2007;52(1):64.

[7] Oshina H, Sotome S, Yoshii T, Torigoe I, Sugata Y, Maehara H, et al. Effects of continuous dexamethasone treatment on differentiation capabilities of bone marrow-derived mesenchymal cells. Bone 2007;41(4):575.

[8] Graziani F, D’Aiuto F, Arduino PG, Tonelli M, Gabriele M. Perioperative dexamethasone reduces post-surgical sequelae of wisdom tooth removal. A splitmouth randomized double-masked clinical trial. Int J Oral Maxillofac Surg 2006;35(3):241. 
[9] Stahn C, Lowenberg M, Hommes DW, Buttgereit F. Molecular mechanisms of glucocorticoid action and selective glucocorticoid receptor agonists. Mol Cell Endocrinol 2007;275(1-2):71.

[10] Ebrecht M, Buske-Kirschbaum A, Hellhammer D, Kern S, Rohleder N, Walker B, et al. Tissue specificity of glucocorticoid sensitivity in healthy adults. J Clin Endocrinol Metab 2007;85:3733-9.

[11] Hwang NS, Varghese S, Elisseeff J. Controlled differentiation of stem cells. Adv Drug Deliv Rev 2008;60(2):199.

[12] Breunig M, Bauer S, Goepferich A. Polymers and nanoparticles: intelligent tools for intracellular targeting? Eur J Pharm Biopharm 2008;68(1):112.

[13] Zimmer A, Kreuter J. Microspheres and nanoparticles used in ocular delivery systems. Adv Drug Deliv Rev 1995;16(1):61.

[14] He W, Horn SW, Hussain MD. Improved bioavailability of orally administered mifepristone from PLGA nanoparticles. Int J Pharm 2007;334(1-2):173.

[15] Byrappa K, Ohara S, Adschiri T. Nanoparticles synthesis using supercritical fluid technology - towards biomedical applications. Adv Drug Deliv Rev 2008; 60(3):299.

[16] Li F-Q, Su H, Wang J, Liu J-Y, Zhu Q-G, Fei Y-B, et al. Preparation and characterization of sodium ferulate entrapped bovine serum albumin nanoparticles for liver targeting. Int J Pharm 2008;349(1-2):274

[17] Zhang W, Qiao X, Chen J. Synthesis of silver nanoparticles-effects of concerned parameters in water/oil microemulsion. Mater Sci Eng B 2007;142(1):1.

[18] Matsumura Y. Poly(amino acid) micelle nanocarriers in preclinical and clinical studies. Adv Drug Deliv Rev 2008;60(8):899.

[19] Luten J, van Nostrum CF, De Smedt SC, Hennink WE. Biodegradable polymers as non-viral carriers for plasmid DNA delivery. J Controlled Release 2008;126(2):97.

[20] Lee P-W, Peng S-F, Su C-J, Mi F-L, Chen H-L, Wei M-C, et al. The use of biodegradable polymeric nanoparticles in combination with a low-pressure gene gun for transdermal DNA delivery. Biomaterials 2008;29(6):742.

[21] Stover TC, Kim YS, Lowe TL, Kester M. Thermoresponsive and biodegradable linear-dendritic nanoparticles for targeted and sustained release of a proapoptotic drug. Biomaterials 2008;29(3):359.

[22] Xiang Y, Chen D. Preparation of a novel pH-responsive silver nanoparticle/ poly(HEMA-PEGMA-MAA) composite hydrogel. Eur Polym J 2007;43(10): 4178 .

[23] Muzzarelli RAA, Ilari P, Petrarulo M. Solubility and structure of $N$-carboxymethylchitosan. Int J Biol Macromol 1994;16(4):177.

[24] Oliveira JM, Kotobuki N, Marques AP, Pirraco RP, Benesch J, Hirose M, et al. Surface engineered carboxymethylchitosan/poly(amidoamine) dendrimer nanoparticles for intracellular targeting. Adv Funct Mater 2008;18(12):1840-53.

[25] Hayashi R, Wada H, Ito K, Adcock IM. Effects of glucocorticoids on gene transcription. Eur J Pharmacol 2004;500:51-62.

[26] Zhang X, Ognibene CM, Clark AF, Yorio T. Dexamethasone inhibition of trabecular meshwork cell phagocytosis and its modulation by glucocorticoid receptor b. Exp Eye Res 2007;84:275-84.

[27] Oliveira JM, Rodrigues MT, Silva SS, Malafaya PB, Gomes ME, Viegas CA, et al. Novel hydroxyapatite/chitosan bilayered scaffold for osteochondral tissueengineering applications: scaffold design and its performance when seeded with goat bone marrow stromal cells. Biomaterials 2006;27(36):6123.

[28] Gomes ME, Godinho JS, Tchalamov D, Cunha AM, Reis RL. Alternative tissue engineering scaffolds based on starch: processing methodologies, morphology, degradation and mechanical properties. Mater Sci Eng C 2002; 20(1-2):19.
[29] Mendes SC, Bezemer J, Claase MB, Grijpma DW, Bellia G, Degli-Innocenti F, et al. Evaluation of two biodegradable polymeric systems as substrates for bone tissue engineering. Tissue Eng 2003;9(1):91-101.

[30] Oliveira AL, Malafaya PB, Costa SA, Sousa RA, Reis RL. Micro-computed tomography ( $\mu-\mathrm{CT})$ as a potential tool to assess the effect of dynamic coating routes on the formation of biomimetic apatite layers on 3D-plotted biodegradable polymeric scaffolds. J Mater Sci Mater Med 2007;18:211-23.

[31] Gomes ME, Azevedo HS, Moreira AR, Ellä V, Kellomäki M, Reis RL. Starchpoly(caprolactone) and starch-poly(lactic acid) fibre-mesh scaffolds for bone tissue engineering applications: structure, mechanical properties and degradation behaviour. J Tissue Eng Regen Med 2008;2(5):243-52.

[32] Chen X-G, Park H-J. Chemical characteristics of O-carboxymethyl chitosans related to the preparation conditions. Carbohydr Polym 2003;53:355-9.

[33] Kotobuki N, Motohiro H, Machida H, Katou Y, Muraki K, Takakura Y, et al. Viability and osteogenic potential of cryopreserved human bone marrowderived mesenchymal cells. Tisssue Eng 2005;11:663-73.

[34] Tanaka T, Hirose M, Kotobuki N, Ohgushi H, Furuzono T, Sato J. Nano-scaled hydroxyapatite/silk fibroin sheets support osteogenic differentiation of rat bone marrow mesenchymal cells. Mater Sci Eng C 2007;27:817-23.

[35] Kotobuki N, Kawagoe D, Nomura D, Katou Y, Muraki K, Fujimore H, et al. Observation and quantitative analysis of rat bone marrow stromal cells cultured in vitro on newly formed transparent b-tricalcium phosphate. J Mater Sci Mater Med 2006;17:33-41.

[36] Karageorgiou V, Kaplan D. Porosity of 3D biomaterial scaffolds and osteogenesis. Biomaterials 2005;26:5474-91.

[37] Leberbauer C, Boulme F, Unfried G, Huber J, Beug H, Mullner EW. Different steroids co-regulate long-term expansion versus terminal differentiation in primary human erythroid progenitors. Blood 2005;105(1):85-94.

[38] Li JP, Habibovic P, van den Doel M, Wilson CE, de Wijn JR, van Blitterswijk CA, et al. Bone ingrowth in porous titanium implants produced by $3 \mathrm{D}$ fiber deposition. Biomaterials 2007;28(18):2810.

[39] Silva MMCG, Cyster LA, Barry JJA, Yang XB, Oreffo ROC, Grant DM, et al. The effect of anisotropic architecture on cell and tissue infiltration into tissue engineering scaffolds. Biomaterials 2006;27(35):5909.

[40] Miot S, Woodfield T, Daniels AU, Suetterlin R, Peterschmitt I, Heberer M, et al. Effects of scaffold composition and architecture on human nasal chondrocyte redifferentiation and cartilaginous matrix deposition. Biomaterials 2005;26(15):2479.

[41] Pittenger MF, Mackay AM, Beck SC, Jaiswal RK, Douglas R, Mosaca JD, et al. Multilineage potential of adult human mesenchymal stem cells. Science $1999 \cdot 284: 143-7$

[42] Kotobuki N, Ioku K, Kawagoe D, Fujimori H, Goto S, Ohgushi H. Observation of osteogenic differentiation cascade of living mesenchymal stem cells on transparent hydroxyapatite ceramics. Biomaterials 2005;26:779-85.

[43] Beck GR, Zerler B, Moran E. Phosphate is a specific signal for induction of osteopontin gene expression. Proc Nat Acad Sci 2000;97:8352-7.

[44] Eijken M, Koedam M, van Driel M, Buurman CJ, Pols HAP, van Leeuwen JPTM. The essential role of glucocorticoids for proper human osteoblast differentiation and matrix mineralization. Mol Cell Endocrinol 2006;248:87-93.

[45] Yoshikawa T, Ohgushi H, Okumura M, Tamai S, Dohi Y, Moriyama T. Biochemical and histological sequences of membranous ossification in ectopic site. Calcif Tissue Int 1992;50:184-8.

[46] Hing KA, Best SM, Tanner KE, Bonfield W. Biomechanical assessment of bone ingrowth in porous hydroxyapatite. J Mater Sci Mater Med 1997;8:731-6. 